\title{
nature
}

6 January 2005 Volume 433 Issue no 7021

\section{A divided world}

The lack of preparation for last month's tsunami illustrates shocking disparities in how science is applied in different regions of the world. The global response to the disaster offers a glimmer of hope that these disparities will be addressed.

A $s$ the full horror of the Asian tsunami sinks in, the reactions of scientists echo those of the population as a whole. These range from a sense of hopelessness in the face of nature's power to concern for the victims and a determination that their suffering should be addressed.

The Indian Ocean tsunami of 26 December 2004 occurred at about 01:00 GMT, when the Indian tectonic plate moved underneath the neighbouring Burma microplate, raising it by about 10 metres along a length of more than $1,000 \mathrm{~km}$ and sending a wave propagating through the full depth of the overlying ocean at high speed. With wavelengths much larger than the depth of the ocean, such waves propagate across the great distances of the open sea without much surface perturbation and with very little energy loss, until shallower coastal shelves slow the wave and increase its amplitude — resulting, in this case, in a calamity of biblical proportions.

Such disasters have always been with us, but this particular event (see News, pages 3-5) had some characteristics that cry out for a global response that is more emphatic and sustained than a brief outburst of charity.

The most distinctive of these characteristics is the uneasy feeling, prompted by the delayed action of the tsunami, that a great deal of the suffering could have been avoided. Much of the damage, after all, occurred in Sri Lanka and on India's eastern coast about two hours after an earthquake had triggered the tsunami in the ocean. Monitoring stations in Japan and the United States, for example, had been able to observe the event in real time and yet apparently could do nothing - despite the ubiquity of modern telecommunications - to warn victims of the impending risk.

It turns out, on closer examination, that not all of this is true. The size of the earthquake wasn't apparent at first glance: early estimates put it at magnitude 8 , which is not exceptional for submarine quakes and is an order of magnitude smaller than the eventual value of 9 that made this the world's largest seismic event for 40 years. And, in the absence of an ocean-based monitoring system, remote seismologists did not know that the quake had triggered a tsunami. Many researchers who were alerted to the event in the United States on their Christmas night, for example, went to bed quite oblivious to the carnage that was unfolding as they slept.

Additionally, as the awful scale of the disaster slowly emerged from remote regions of western Indonesia, it has become clear that most of the death and destruction had occurred in a region that was too close to the epicentre of the event for warnings to have made much difference.

\section{Neglect}

Nonetheless, an effective warning system, allied to a public education campaign of the sort that has already taken place around the Pacific Ocean, could have reduced the scale of the disaster.

It is clear, with the benefit of hindsight, that the arcane international bodies that manage tsunami protection have been neglected and underfunded for many years. Most of them have focused on the Pacific Ocean, and occasional attempts to widen their brief to the Indian Ocean have been rebuffed.
A master plan prepared in 1999 by ITSU, one of the international organizations that plans for the monitoring of tsunamis, stated: "Tsunami hazards exist on both sides of the Atlantic Ocean, in the eastern Indian Ocean, and in the Mediterranean, Caribbean, and Black Seas. Efforts to establish warning centers in those areas should be encouraged."

An important reason for the previous confinement of monitoring systems to the Pacific has been the occurrence of two tsunamis in the Pacific quite recently, in 1960 and 1964. The last tsunami produced by an earthquake in the Indian Ocean is thought to have occurred back in 1833 .

However, the most important differentiating factor has been the readiness of 'Pacific rim' nations such as Japan, Australia and the United States to support a cheap but potentially effective system for monitoring and for educating the public about an infrequent risk. India, Indonesia and the other nations on the Indian Ocean's rim are relatively poor countries with needs that seemed more pressing than that of planning against the remote — but nonetheless inevitable prospect of a tsunami.

\section{Pushing for change}

A great amount could have been done at relatively little expense to plan for a tsunami, however. The most important component of such preparation is public education, so that local inhabitants are aware, for example, of the fact that a dramatic recession of the ocean is in itself a warning of an impending event. The next most important component is the construction of a simple network that will quickly convey warning information from the seismological stations to some central point (such as the Pacific Tsunami Warning Center in Hawaii) and back out again to local radio and television channels, perhaps using siren systems in regions that can afford them.

Some of this will doubtless now take place — and so it must. As earthquake-mitigation programmes in Japan and California have shown, we can avoid vast carnage in the face of major natural disruptions. Scientists have a role to play in this. Biomedical researchers have taken global initiatives to address preventable deaths from tropical diseases that might otherwise be ignored. In the same spirit, Earth scientists around the world must now press even harder for resources in rich countries to be brought to bear to confront the risks of natural disasters in poor countries.

The same communications technologies that could have helped to mitigate this disaster have, instead, brought it home relentlessly to our living rooms. The science behind the event has been busily and prominently displayed for all to see - alongside the consequences of inaction in the face of well-established risks.

Is it too much to expect that people in rich countries, when confronted with evidence on such a scale, will ask that their governments start to pay modest respect to the value of human life amongst the poor, and adjust their budgetary priorities accordingly? Scientists, at least, should argue for a strengthening of research priorities that reflect the needs not of well-protected interest groups in their own nations, but of humanity itself. 